\title{
UV - Visible Spectrophotometric Quantification of Total Polyphenol in Selected Fruits
}

\author{
Terefe Tafese Bezuneh, Eyob Mulugeta Kebede \\ Department of Chemistry, Arbaminch University, Arbaminch, Ethiopia
}

Email address:

teretafe@gmail.com (T. T. Bezuneh)

To cite this article:

Terefe Tafese Bezuneh, Eyob Mulugeta Kebede. UV - Visible Spectrophotometric Quantification of Total Polyphenol in Selected Fruits. International Journal of Nutrition and Food Sciences. Vol. 4, No. 3, 2015, pp. 397-401. doi: 10.11648/j.ijnfs.20150403.28

\begin{abstract}
Fruits are known as a richest source of bioactive compounds as polyphenols which are known to have significant health promoting properties. The present study investigates the total polyphenol content of some selected fruits extracted in: acidified $70 \%$ ethanol, acidified $70 \%$ methanol, acidified $70 \%$ acetone, and $100 \%$ water solvents. Standard gallic acid solution prepared in the range of $50-500 \mu \mathrm{g} / \mathrm{L}$ was used to plot a calibration graph. A good linearcalibration graph $(\mathrm{r}=0.998, \mathrm{n}=3)$ was obtained by plotting absorbance at $511 \mathrm{~nm}$ versus standard solution and all results are given as gallic acid equivalent (GAE, mg/g, dry weight). The concentration of total polyphenols varies with the solvent used and also among different samples. Higher concentration was detected in papaya fruit both in the peel and pulp $(238.6 \pm 3.64,135.2 \pm 0.09 ; \mathrm{GAE}, \mathrm{mg} / \mathrm{g}$, dry weight) respectively and lower concentration in banana peel and pulp $(43.2 \pm 0.13,26.6 \pm 0.06 ; \mathrm{GAE}, \mathrm{mg} / \mathrm{g}$, dry weight) respectively.
\end{abstract}

Keywords: Gallic Acid, Antioxidant, Total-Polyphenol

\section{Introduction}

Reactive oxygen species (ROS) and reactive nitrogen species (RNS) may be produced in the cell during normal aerobic metabolism in living organisms. The ROS and RNS are oxygen and nitrogen based radicals as: superoxide anion $\left(\mathrm{O}^{2-}\right)$, alkoxyl $\left(\mathrm{RO}^{-}\right)$, peroxyl $\left(\mathrm{ROO}^{-}\right)$, hydroxyl radical $\left(\mathrm{OH}^{-}\right)$, peroxides $\left(\mathrm{H}_{2} \mathrm{O}_{2}\right)$, peroxynitrite $\left(\mathrm{ONOO}^{-}\right)$, and nitric oxide radicals (NO) [1, 2].

The production of reactive radicals ROS and RNS in the animal cell can alter the normal function of the cell. Their highly reactive nature leads them causing much damage to the cell and cell components as: carbohydrates, proteins, lipids, DNA and RNA, which lead to cell death and tissue damage [3-5].

Accumulation of reactive radicals (ROS and RNS) in the cell results in imbalance between the production of oxidative species and the protection system by antioxidants in the cell [6]. Oxidative stress is an imbalance state between production of free radicals and that of the antioxidant defense capacity of the cell [7].

Oxidative stress results in propagation of the oxidative chain through lipid peroxidationwhich is responsible for the development of human diseases such as: cancer, cardiovascular disease, multiple sclerosis, autoimmune disease, Parkinson's disease, eye diseases, cellular aging, coronary heart disease, diabetes, mutagenesis and neurodegenerative infections [8-10].

Antioxidantsreduce the oxidative stress in the cell by neutralizing free radicals. They neutralize radicals by donating an electron or hydrogen to the free radicals, thus protecting cell components from potential damage $[11,12,44]$.

Antioxidants prevent the formation of oxidative stress through different mechanisms. The first one is that, antioxidants are known to chelate metal ions such as copper and iron ions. In doing so, they prevent the metal-catalyzed formation of reactive radical species (ROS, RNS). Secondly, their free radical scavenging properties enable them to minimize the concentration of free reactive radicals. Thirdly, they inhibit enzymes that might activate formation of free radicals in the cell [13].

Fruits in the human diet contain bioactive compounds which are attributing these fruits for preventing various health related problems $[14,15]$. Fruits are listed as the richest source of polyphenols, a class of plant-based bioactive molecules [16, 17]. Polyphenols are secondary plant metabolites characterized by the presence of one or more hydroxyl functional group attached to a single or to multiple aromatic 
rings $[18,19]$.

The chemical structure of polyphenols varies from that of a simple phenolic molecule, such as phenolic acid and phenolic alcohols with only one phenol ring to that of a complex high-molecular mass polymer [20,18]. Polyphenols can be subdivided into several classes based on their chemical structure. They are mainly classified as: Flavonoids, quinones, tannins, lignins, coumarins, anthocyanins, phenolic acids, phenolic alcohols, stilbenes and lignans [21,43]. Flavonoids are widely distributed in plant tissues and are responsible for the colour of some plantsand plant bodies. They are classified as: flavonols, flavones, flavanones, isoflavones, anthocyanidins and flavanols (catechins and proanthocyanidins) [22-24].

Different factors including: degree of ripeness [25], variety [26], storage conditions [27], soil composition, geographic location and climate are factors responsible for the variation in the concentration of phenolic compounds in fruits. This variation in concentration of phenolic compounds attributes fruits with their difference in colour, taste andflavour [20].

The antioxidant and metal chelating capacity of polyphenols are responsible for reducing the risk of oxidative damage to the cell $[11,42]$. This property makes polyphenols a protective agent against so many degenerative and infectious diseases. Different in vivo and in vitro investigations supported the connection between the antioxidant nature of polyphenols and the reduction in the risk of cardiovascular disease (CVD) [28, 29], cancer [30,31,45], osteoporosis, diabetes mellitus, neurodegenerative disease, oral diseases, atherosclerosis, aging and other degenerative diseases [32-37].

The main objectives of the present study were to determine the total polyphenol composition of selected fruits. The solvents used to extract phenolic compounds formfruit sample matrics for the present study were: $70 \%$ acidified ethanol in water, $70 \%$ acidified acetone in water, $70 \%$ acidified methanol in water and $100 \%$ water solvents.

\section{Materials and Methods}

\subsection{Apparatus}

All spectrophotometric measurements were made on a SP65 UV/Visible spectrophotometer (Gallenkamp, UK) using a $1.0 \mathrm{~cm}$ optical path length glass cell.

\subsection{Reagents and Chemicals}

Gallic acid (Riedel-de Haen), Ethanol (Avonchem, UK), Acetone (Essex, UK), Methanol (Merk, Brazil), Iron(III)chloride hexahydrate (Guangdong Guanghua, China), 1,10 phenanthroline hydrate (Fisher Scientific, UK), Ethylene diaminetetraaceticaciddihydrate (Avonchem, UK), Potassium Acetate (Park, UK), Glacial acetic acid (Avonchem, UK), Hydrochloric acid, are chemicals that were used in this study. All reagents and chemicals were of analytical grade and double distilled water was used to prepare solutions.

\subsection{Procedure}

\subsubsection{Sample Collection and Preparation}

The fresh fruit samples: Banana (Musa acuminate),Mango (Mangiferaindica L.), Papaya (Carica Papaya), Avocado (Persea Americana), and Apple (Malusdomestica) samples were collected randomly from a local market in Arbaminch town, Ethiopia.

Randomly selected fruit samples were taken to the laboratory for analysis.Only fruit samples with no apparent physical or microbial damage were selected. The samples were washed to remove dirt particles on the surface of the samples and the peel and flesh of each fruit samples were separated manually. These peel and flesh samples were then sliced separately into pieces using scalpeland oven-dried at $60^{\circ} \mathrm{C}$ for two days. The oven-dried samples were gound to a powder using a mortar and pestle and then sieved using mesh sieve of $2 \mathrm{~mm}$ diameter and stored in polyethylene bag until required for analysis.

\subsubsection{Extraction}

The efficiency of the extraction of polyphenols from different sample matrices depends greatly on the nature of the solvent used, extraction time, extraction temperature and solvent to sample ratio. This is because of the diverse nature of phenolic compounds. Different solvents have been used for this purpose where methanol, ethanol, acetone, and their combinations with different proportions of water have been used most frequentlyfor the extraction of phenolics from plant materials [45-47].

For the present investigation, acidified $70 \%$ acetone in water $(7: 3, v / v), 70 \%$ acidified ethanol in water $(7: 3, v / v), 70 \%$ acidified methanol in water $(7: 3, \mathrm{v} / \mathrm{v})$ and $100 \%$ water were used as solvent to extract total polyphenolic compounds from the selected fruit samples.

Extraction procedures have been performed byhomogenizing $1 \mathrm{~g}$ oven dried fruit sample in $45 \mathrm{~mL}$ of the desired solvent at $5{ }^{\circ} \mathrm{C}$ for 2 hours on a hot plate. The extract was filtered through Whatman No.41filter paper. One milliliter of the filtrates were transferred to $25 \mathrm{~mL}$ volumetric flask and made up with double distilled water to the mark and stored at $-5{ }^{\circ} \mathrm{Cuntil}$ used for analysis of the total phenolics.

\subsubsection{Determination of Total Polyphenol Content}

The procedure developed by Mônicaet al. have been adopted for the quantification of total polyphenols in 5 different fruit samples with slight differences, namely the standard solution used was gallic acid instead of pyrogallicacid [38].

One milliliter $(1 \mathrm{~mL})$ of each sample extract was transferred to a different $25 \mathrm{~mL}$ volumetric flask containing $2.5 \mathrm{~mL}$ of 3.54 $\mathrm{g} \cdot \mathrm{L}^{-1}$ Iron(III)chloridehexahydrate $\left(\mathrm{FeCl}_{3} \cdot 6 \mathrm{H}_{2} \mathrm{O}\right)$ solution. The volumetric flask containing the sample solution was then placed in a water bath and maintained at $80^{\circ} \mathrm{C}$ for $20 \mathrm{~min}$. After this, $2.5 \mathrm{~mL}$ of acetate buffer $\left(\mathrm{CH}_{3} \mathrm{COOH} / \mathrm{CH}_{3} \mathrm{COOK}\right)$ solution $\quad(\mathrm{pH} 4.6), \quad 5.0 \quad \mathrm{~mL} \quad$ of $3.28 \quad \mathrm{~g} \cdot \mathrm{L}^{-1}$ 1,10-phenanthrolinehydrate (1,10-phen) and $2.5 \mathrm{~mL}$ of $3.72 \mathrm{~g}$ $\mathrm{L}^{-1}$ Ethylene diaminetetraaceticaciddihydrate (EDTA) solutions were added, respectively. Finally, each flask was 
filled to the mark with distilled water, cooled and then the absorbance measurements were made at $511 \mathrm{~nm}$.

\subsubsection{Statistical Analysis}

Data were expressed as mean \pm standard deviation (SD) and evaluated by one way analysis of variance (ANOVA) using Statistical Packages for the Social Sciences (SPSS) software. Significant level used was $\mathrm{p}<0.05$ for all data analyzed.

\section{Results and Discussion}

In this study, 5 different fruits were investigated for their total phenolic compounds (TP). The results obtained for the total polyphenol quantification in pulp and peel of different fruit samples were presented in Table 1.

Table 1. Total polyphenol content of fruits expressed as $m g$ GAE/g, dry weight ( $n=3)$.

\begin{tabular}{|c|c|c|c|c|c|}
\hline \multirow{3}{*}{$\begin{array}{l}\text { Fruits } \\
\text { tissue }\end{array}$} & \multirow{3}{*}{ Fruits } & \multicolumn{4}{|c|}{ Total polyphenol content (mg GAE/g, dry weight) } \\
\hline & & \multicolumn{4}{|c|}{ Extraction Solvents } \\
\hline & & Ethanol & Methanol & Acetone & Water \\
\hline \multirow{5}{*}{ Pulp } & Mango (Mangiferaindica L.) & $28.40 \pm 0.12^{a}$ & $26.80 \pm 0.12^{\mathrm{a}}$ & $41.20 \pm 0.08^{\mathrm{a}}$ & $65.90 \pm 0.00^{\mathrm{a}}$ \\
\hline & Banana (Musa acuminate) & $31.90 \pm 0.07^{\mathrm{a}}$ & $26.60 \pm 0.06^{\mathrm{a}}$ & $94.40 \pm 0.09^{\mathrm{a}}$ & $74.10 \pm 0.05^{\mathrm{a}}$ \\
\hline & Avocado (Persea Americana) & $32.10 \pm 0.17^{\mathrm{a}}$ & $31.20 \pm 0.14^{\mathrm{a}}$ & $76.40 \pm 0.07^{\mathrm{a}}$ & $53.70 \pm 0.44^{\mathrm{a}}$ \\
\hline & Apple (MalusDomestica) & $44.70 \pm 0.13^{\mathrm{a}}$ & $45.90 \pm 0.24^{\mathrm{a}}$ & $131.50 \pm 0.07^{\mathrm{a}}$ & $86.40 \pm 1.03^{\mathrm{a}}$ \\
\hline & Papaya (Carica Papaya) & $53.00 \pm 0.18^{\mathrm{a}}$ & $39.10 \pm 0.08^{\mathrm{a}}$ & $135.20 \pm 0.09^{\mathrm{a}}$ & $122.30 \pm 0.13^{\mathrm{a}}$ \\
\hline \multirow{4}{*}{ Peel } & Banana (Musa acuminate) & $77.70 \pm 0.09^{\mathrm{a}}$ & $74.80 \pm 1.67^{\mathrm{a}}$ & $76.00 \pm 0.08^{\mathrm{a}}$ & $43.20 \pm 0.13^{\mathrm{a}}$ \\
\hline & Avocado (Persea Americana) & $188.80 \pm 0.12^{\mathrm{a}}$ & $192.10 \pm 0.07^{\mathrm{a}}$ & $188.80 \pm 0.12^{\mathrm{a}}$ & $157.1 \pm 0.07^{\mathrm{a}}$ \\
\hline & Apple (MalusDomestica) & $109.00 \pm 0.07^{\mathrm{a}}$ & $87.70 \pm 0.15^{\mathrm{a}}$ & $92.10 \pm 0.08^{\mathrm{a}}$ & $84.80 \pm 0.20^{\mathrm{a}}$ \\
\hline & Papaya (Carica Papaya) & $238.63 \pm 3.64^{\mathrm{a}}$ & $204.20 \pm 0.07^{\mathrm{a}}$ & $227.90 \pm 0.08^{\mathrm{a}}$ & $147.60 \pm 0.13^{\mathrm{a}}$ \\
\hline
\end{tabular}

All data are presented as mean \pm SD of the three replicates $(n=3)$. Similar superscript alphabets within the same column indicates significant different $(\mathrm{p}<0.05)$

As it has been reported in different investigations selection of solvent has significant effect on the extraction of polyphenols from different sample matrixes. In the present investigation the extraction ability of each solvent used for the extraction purpose vary significantly at $\mathrm{P}<0.05$.

As can be seen from the results, higher total polyphenolin pulp was found in papaya 135.2 $\pm 0.09 \mathrm{GAE}$ (mg/g, dry weight), whereas the lowest values were found in banana $26.6 \pm 0.06$ GAE (mg/g, dry weight). In peel, the highest total polyphenolcontent was found in papaya 238.6 $\pm 3.64 \mathrm{GAE}$ (mg/g, dry weight), whereas the lowest values were found in banana $43.2 \pm 0.18 \mathrm{GAE}(\mathrm{mg} / \mathrm{g}$, dry weight). Hence, both in pulp and peel samples a higher concentration of total polyphenolswas recorded in papaya samples and lower concentration in banana samples. Significant amounts of phenolic compounds were extracted in water as the solvent both in the pulp and the peel of fruit samples.

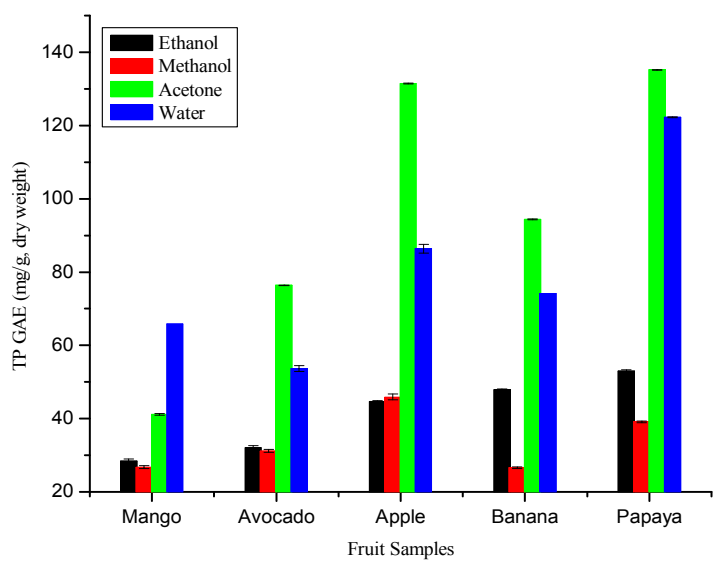

Figure 1. Concentration of total polyphenols expressed as GAE ( $\mathrm{mg} / \mathrm{g}$, dry weight) in pulp of fruit samples extracted in the solvent indicated in the legend.

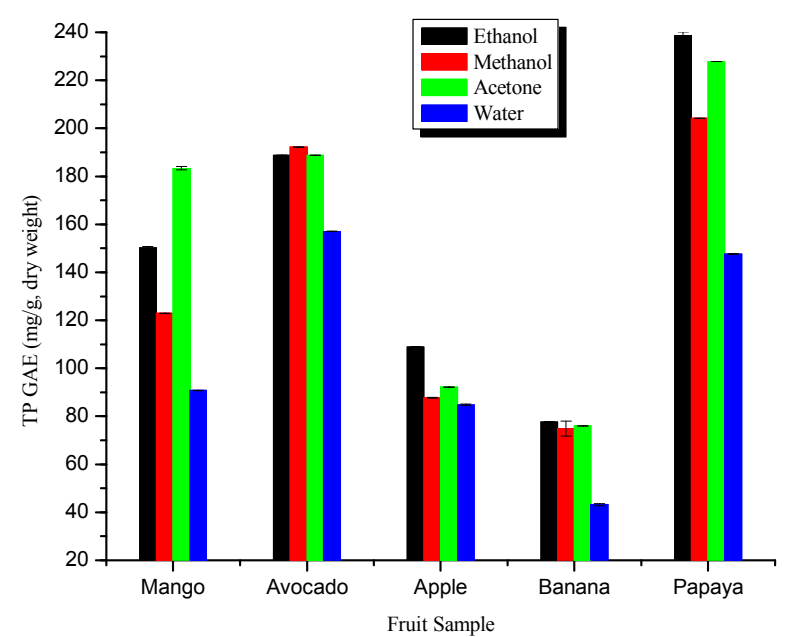

Figure 2. Concentration of total polyphenols expressed as GAE ( $\mathrm{mg} / \mathrm{g}$, dry weight) in peel of fruit samples extracted in the solventindicated in the legend.

Previous reports have revealed the presence of higher concentrations of total polyphenols in peel of fruit compared to that of the pulp. A study by Hana et al., reported that mango peel exhibited a higher total polyphenolcontent compared to the pulp [39]. Carolinaet al. has also reported a higher total polyphenolconcentration in the peel of apple than the pulp [34]. The same was reported by Fatemehet al. for banana fruit. In that report, the total polyphenolconcentration in banana peel was almost 2-fold higher than in the pulp [41].

Hence, the results we obtained are in accordance with these previous reports, namely that higher concentrations of total polyphenolshave been recorded in the peel of the fruit compared to other edible parts of the fruit. The total polyphenol content of fruits in peel varied significantly $(\mathrm{P}<$ 0.05 ) from that of the pulp. Thiswas true for all fruit samples selected for this investigation,regardless of the solvent used. 


\section{Conclusion}

Fruits can be listed as a principal source of polyphenols, a group of plant-based bioactive compounds. Various in vitro and in vivo investigations revealed the significant importance of polyphenols in preventing various human degenerative diseases. The present study investigated the composition of phenolic compounds in the peel and pulp of selected fruits. This study showed that a higher concentration of total polyphenol was found in the fruit peel than in the pulpof the fruits included in the study.

\section{References}

[1] Maliwan A, Wongduan S, Saowanee L, et al. (2013). Rapid Screening Method for Assessing Total Phenolic Content Using Simple Flow Injection System with Laccase based-biosensor. International Journal of Electrochemical Science, 8, 10526 10539.

[2] Takako Y, Jeong S N, and Chan H P (2013). Green Tea Polyphenols for the Protection against Renal Damage Caused by Oxidative Stress. Hindawi Publishing Corporation, 1-11.

[3] Maisarah A M, Asmah R and Fauziah O (2014). Proximate Analysis, Antioxidant and Antiproliferative Activities of Different Parts of Carica Papaya. Journal of Nutrition and Food Science, 4(2), 1-7.

[4] Wei Q L, Jian G X (2014). Profile of DNA damage protective effect and antioxidant activity of different solvent extracts from the pericarp of Garciniamangostana. Journal of Food and Nutrition Sciences, 3(1), 1-6.

[5] Chwan L S, Ming C C, and Jia S W (2013). Tea and bone health: steps forward in translational nutrition. American Journal of Clinical Nutrition, 98(1), 1694S-1699S.

[6] Giuseppina PP L, Fabio V, Camila R C, et al. (2014). Polyphenols in Fruits and Vegetables and Its Effect on Human Health. Food and Nutrition Sciences, 5, 1065-1082.

[7] Rajan M and Thangaraj P (2014). Comparative evaluation of different extraction methods for antioxidant and anti-inflammatory properties from OsbeckiaparvifoliaArn. An in vitro approach. Journal of King Saud University Science, $26,267-275$.

[8] Sahin K, Orhan C, Tuzcu M, et al. (2010). Epigallocatechin-3-gallate prevents lipid peroxidation and enhances antioxidant defense system via modulating hepatic nuclear transcription factors in heat-stressed quails. Poultry Science, 89, 2251-2258.

[9] Cestmir C and Jitka C (2015). Oxidative Stress to the Cornea, Changes in Corneal Optical Properties, and Advances in Treatment of Corneal Oxidative Injuries. Hindawi Publishing Corporation, 1-10.

[10] Jeanelle B and Rui H L (2004). Apple phytochemicals and their health benefits. Nutrition Journal, 3, 1-15.

[11] Mohammed S, Hamzat I T, Bashir M A, et al. (2013). An overview of natural plant antioxidants: analysis and evaluation. Advances in Biochemistry, 1(4), 64-72.

[12] Stefano P, Crispian S (2009). Polyphenols, oral health and disease: A review. Journal of dentistry, 37, 413-423.
[13] Balz F and Jane V H (2003). Antioxidant Activity of Tea Polyphenols In Vivo: Evidence from Animal Studies. The Journal of Nutrition, 133, 3275S-3284S.

[14] Nikita L and Chaitanya S (2012). Polyphenols and oral health. RSBO, 9(1), 74-84.

[15] Palafox C H, Yahiab E, Islas O M, et al. (2012). Effect of ripeness stage of mango fruit (MangiferaindicaL.,cv.Ataulfo) on physiological parameters and antioxidant activity. ScientiaHorticulturae, 135, 7-13.

[16] Massimo A, Carmela F, Roberta B, et al. (2007). Polyphenols, dietary sources and bioavailability. Ann InstitutoSuperiore di Sanita, 43(4), 348-361.

[17] Alecia S M, Dai Q, Xiao O S, et al. (2003). Intake of Fruits, Vegetables and Selected Micronutrients in Relation To the Risk of Breast Cancer. International Journal of Cancer, 105, 413-418.

[18] Constantine D S (2007). Extraction, separation, and detectionmethods for phenolic acids and flavonoids. Journal of Separation Science, 30, 3268-3295.

[19] Claudine M, Augustin S, Christine M, et al. (2004). Polyphenols: food sources and bioavailability. American Journal of Clinical Nutrition, 79, 727-47.

[20] Charles W H, Giselle M M, Manuel S V et al. (2012). Phenolic compounds in fruits-an overview. International Journal of Food Science and Technology, 47, 2023-2044.

[21] Koffi E, Sea T, DodeheY,et al. (2010). Effect of solvent type on extraction of polyphenols from twenty three Ivorian plants. Journal of Animal and Plant Sciences, 5(3), 550-558.

[22] Usune E, Alfredo F Q, Fermín I M, et al. (2013). Impact of Polyphenols and Polyphenol-Rich Dietary Sources on Gut Microbiota Composition. Journal of Agricultural and Food Chemistry, 61, 9517-9533.

[23] Koen B, Ruth V, Guido V, et al. (2004). Induction of Cancer Cell Apoptosis by Flavonoids Is Associated with Their Ability to Inhibit Fatty Acid Synthase Activity. The Journal of Biological Chemistry, 280(7), 5636-5645.

[24] Ali K, Meredith A W and Thomas H R (2013). Techniques for Analysis of Plant Phenolic Compounds. Molecules, 18, 2328-2375.

[25] Nemanja M, Branko P, Olga M, et al. (2012). Phenolic content and antioxidant capacity of fruits of plum cv. 'Stanley' (Prunusdomestica L.) as influenced by maturity stage and on-tree ripening. Australian Journal of Crop Science, 6(4), 681-687.

[26] Merlene A B, Suriyakala M A, and Gothandam K M (2012). Varietal Impact on Phytochemical Contents and Antioxidant Properties of Musa acuminata (Banana). Journal of Pharmaceutical Science and Research, 4(10), 1950-1955.

[27] Oruma P, Prapasri P, Anadi N, et al. (2008). Changes of antioxidant activity and total phenolic compounds during storage of selected fruits. Journal of Food Composition and Analysis, 21, 241-248.

[28] Joseph A V (2005). Polyphenols and cardiovascular disease: effects on endothelial and platelet function. American Journal of Clinical Nutrition, 81(1), 292S-7S. 
[29] David V, Ana R M, Giulia C, et al. (2010). Polyphenols and Human Health: Prevention of Disease and Mechanisms of Action. Nutrients, 2, 1106-1131.

[30] Moushumi L C, Santosh K K, Rajiv R M, et al. (1999). A Flavonoid Antioxidant, Silymarin, Affords Exceptionally High Protection against Tumor Promotion in the Sencar Mouse Skin Tumorigenesis Model. Cancer Research, 59, 622-632.

[31] Ilja C A and Peter C H (2005). Polyphenols and disease risk in epidemiologic studies. American Journal of Clinical Nutrition, 81(1), 317S-25S.

[32] Patricia G S, Aranzazu M S, Antonio S C, (2010). Phenolic Compound Extraction Systems for Fruit and Vegetable Samples. Molecules, 15, 8813-8826.

[33] Lizbeth A C, Jemina T C, Angel M M, et al. (2014). Antioxidant Capacity and Total Phenolic Content in Fruit Tissues from Accessions of Capsicum chinenseJacq. (Habanero Pepper) at Different Stages of Ripening. Hindawi Publishing Corporation, 1-5.

[34] Carolina H, Sergio A, Italo C, et al. (2010). Determination of Antioxidant Capacity, Total Phenolic Content and Mineral Composition of Different Fruit Tissue of Five Apple Cultivars Grown in Chile. Chilean Journal of Agricultural Research, 70(4), 523-536.

[35] David O K (2014). Polyphenols and the Human Brain: Plant "Secondary Metabolite" Ecologic Roles and Endogenous Signaling Functions Drive Benefits. Advanced in Nutrition, 5 , 515-533.

[36] Manmohan S and Purnima R (2013). Antioxidant Activity, Total Flavonoid and Total Phenolic Content of Musa acuminate Peel Extracts. Global Journal of Pharmacology, 7 (2), 118-122.

[37] Rong T (2010). Chemistry and Biochemistry of Dietary Polyphenols. Nutrients, 2, 1231-1246.

[38] Mônica G S, Cecilia V N, Horacio D M (2013). A new method for quantification of total polyphenol content in medicinal plants based on the reduction of $\mathrm{Fe}(\mathrm{III}) / 1,10$-phenanthroline complexes. Advances in Biological Chemistry, 3, 525-535.

[39] Hana K, Jeong Y M, Hyeonji K et al. (2010). Antioxidant and anti-proliferative activities of mango (Mangiferaindica L.) flesh and peel. Food Chemistry, 121, 429-436.

[40] Fatemeh S R, Saifullah R, Abbas F M A et al. (2012). Total phenolics, flavonoids and antioxidant activity of banana pulp and peel flours: influence of variety and stage of ripeness. International Food Research Journal, 19 (3), 1041-1046.

[41] Michalak A (2006). Phenolic Compounds and Their Antioxidant Activity in Plants Growing under Heavy Metal Stress. Polish Journal of Environmental Study, 15(4), 523-530.

[42] Andressa B, Gisely C L and João C P M (2013). Application and Analysis of the FolinCiocalteu Method for the Determination of the Total Phenolic Content from LimoniumBrasiliense L. Molecules, 18, 6852-6865.

[43] Shizuo T (2011). Polyphenol Content and Antioxidant Effects in Herb Teas. Chinese Medicine, 2, 29-31.

[44] Jin D and Russell J M (2010). Plant Phenolics: Extraction, Analysis and Their Antioxidant and Anticancer Properties. Molecules, 15, 7313-7352.

[45] Joshua D L, Jungil H, Guang-yu Y, et al. (2005). Inhibition of carcinogenesis by polyphenols: evidence from laboratory investigations. American Journal of Clinical Nutrition, 81(suppl), 284S-91S.

[46] Nguyen N T, Phan P H, Huynh N O (2015). Optimizing the extraction conditions of phenolic compounds from fresh tea shoot. Journal of Food and Nutrition Sciences, 3(1-2), 106-110.

[47] Dam S M (2015). Study on the extraction of polyphenol from Artocarpusaltilis with ultrasonic wave technology optimized by central composite design-response surface method. Journal of Food and Nutrition Sciences, 3(1-2), 115-118. 